University of Nebraska - Lincoln

DigitalCommons@University of Nebraska - Lincoln

Faculty Publications, Department of Psychology

Psychology, Department of

September 2006

\title{
The environment of child maltreatment: contextual factors and the development of psychopathology
}

Debra B. Hecht

University of Nebraska-Lincoln

David J. Hansen

Univertsity of Nebraska-Lincoln, dhansen1@unl.edu

Follow this and additional works at: https://digitalcommons.unl.edu/psychfacpub

Part of the Psychiatry and Psychology Commons

Hecht, Debra B. and Hansen, David J., "The environment of child maltreatment: contextual factors and the development of psychopathology" (2006). Faculty Publications, Department of Psychology. 26.

https://digitalcommons.unl.edu/psychfacpub/26

This Article is brought to you for free and open access by the Psychology, Department of at DigitalCommons@University of Nebraska - Lincoln. It has been accepted for inclusion in Faculty Publications, Department of Psychology by an authorized administrator of DigitalCommons@University of Nebraska - Lincoln. 


\title{
The environment of child maltreatment: contextual factors and the development of psychopathology
}

\author{
Debra B. Hecht and David J. Hansen \\ Clinical Psychology Training Program, Department of Psychology, University of Nebraska-Lincoln, \\ 238 Burnett Hall, P.O. Box 880308, Lincoln, NE 68588-0308, USA
}

Submitted and accepted in December 1999; online in August 2001; in print in September 2001.

\begin{abstract}
Some professionals have hypothesized that the observed problems in children who have been maltreated may actually be a result of the combination of risk factors surrounding the child, including but not limited to direct results of the abuse itself. This article examines the complexity of hypothesized pathways to poor adjustment after physical and sexual abuse. The literature on the impact of major risk factors associated with maltreatment is reviewed in an attempt to clarify the potential contributions of these contextual variables on the development of psychopathology in physically and sexually abused children. The implications this analysis may yield for prevention, intervention, and research in this field are also discussed.
\end{abstract}

Author Keywords: Child maltreatment; Consequences; Psychopathology; Environment

Child maltreatment is a growing social problem in the US. Each year, more and more cases of abuse are being brought to the attention of professionals. Under the Endangerment Standard of the Third National Incidence Study of Child Abuse and Neglect (NIS-3) conducted in 1993, there were an estimated 2,815,600 abused children who were at risk for harm, which is nearly double the number reported in 1986 (National Center on Child Abuse and Neglect [NCCAN], 1996). Researchers and clinicians have established that the effects of maltreatment are harmful to the socioemotional, behavioral, and cognitive development of children. They have also delineated a multitude of risk factors and correlates, which place a child at risk for being abused (e.g., living in poverty, having a single-parent, parental psychopathol-

Published in Aggression and Violent Behavior 6:5 (September-October 2001), pp. 433-457.

Copyright (C) 2001 Elsevier Science Ltd. Used by permission. 
ogy, etc.). Each of these risk factors has its own unique influence on the development and adjustment of children, and, to further complicate matters, these factors tend to co-exist, perhaps yielding an additive or multiplicative effect on the mental

health of a child. Some professionals have hypothesized that the observed problems in children who have been maltreated may actually be a result of the risk factors surrounding the child, and not necessarily or exclusively a direct result of the abuse itself (e.g., Houck and McClellan). Obvious exceptions to this premise include deficits as a result of physical injuries and some of the sexualized behaviors that are exhibited by children who have been sexually abused.

This article examines the complexity of hypothesized pathways to poor adjustment after physical and sexual abuse. The literature on the impact of major risk factors associated with maltreatment is reviewed in an attempt to better understand the potential contributions of these contextual variables on the development of psychopathology in physically and sexually abused children. The implications this analysis may yield for prevention, intervention, and research in this field are also discussed. Before examining the literature on the ecology of maltreatment, methodological challenges and problems common in the research are briefly considered.

\section{Challenges in maltreatment research}

Child maltreatment has many possible correlates and consequences and tends to crossover many social domains (e.g., legal, medical, psychological, social welfare; Hansen et al., 1998). There are no well-accepted definitions across domains as to what constitutes an abusive act; the legal definition may vary from a practitioner's definition (Ammerman and Hansen). The families involved in child maltreatment comprise a heterogeneous group, and often are undergoing multiple problems and stressors in addition to the abuse or neglect which may be contributing to the expression and/or maintenance of the abuse (Hansen et al., 1998). These factors, as well as others, create problems for researchers trying to uncover etiological trends.

One of the earliest difficulties encountered in this area of research is to agree upon definitions of maltreatment. Given the lack of social consensus on what behaviors constitute abuse, whether the child has to be harmed vs. endangered as a result of the behavior, and disagreement over the importance of the intent of the perpetrator, uniform definitions do not currently exist (Ammerman, 1998). Definitions of abuse often differ depending on the purpose of the research and the intended audience (Kinard, 1994). Different professionals (e.g., law enforcement, medical professionals, CPS) also tend to use different standards. In addition, if a child has experienced multiple forms of abuse, the researcher is left to determine if the effects are cumulative, interactive, or a reflection of the most recent abuse experienced (Kinard, 1994). The time between the abusive act and the assessment also should be considered, as the more time that has elapsed, the greater the chance that intervening variables may play a role (Kinard, 1994).

Sample selection is another area of maltreatment research that causes some difficulty in interpretation and generalizability. Many researchers work in hospital settings or treatment 
facilities, and thus, draw their samples from this particular population while other samples might be selected from shelters, group homes, or schools (Ammerman, 1998). Participants drawn from hospital settings tend to have more severe injuries, and younger children are more likely to be over-represented (Kinard, 1994). Another potential sampling location is from the legal system, and again, these samples may be biased towards the most severe cases, and may tend to over-represent children who are removed from the home. Given the importance of immediate action with these families, random assignment often is not feasible (Hansen et al., 1998). Furthermore, abuse samples commonly include physically abusive and neglect cases, and analyses do not typically differentiate these two groups (Widom, 1989). There may be different mechanisms at work with respect to these two types of maltreatment which prior studies have not been able to illuminate.

Use and selection of comparison groups is critical in this type of research, but also poses some complications. Usually, comparison groups are selected in order to maximize the similarities in life experiences and circumstances which are thought to be influential with respect to the specific hypotheses of the study (Kinard, 1994). The researcher needs to decide whether the matching should occur for the families' current situations or for the context at the time of the abuse (Kinard, 1994). This distinction in itself may have a major impact on the results of the study, depending on the changes that occurred as a result of the abuse (e.g., the removal of the child or the perpetrator from the home). Also, it can be quite difficult to obtain permission to ensure that these comparison families currently do not have an active case with CPS. In addition, many states protect the rights of families, and expunge cases that have been investigated and are unfounded. Thus, it is possible for a family to have been reported for alleged abuse multiple times, making a researcher suspicious about whether this family really is non-abusive, yet this information is unavailable. Although matching samples is a necessary element, statistical analyses can only control for so many variables; therefore, selection of these variables must be considered carefully. It is possible that the groups may differ significantly on other variables that were deemed less important for the particular analysis, but actually account for variance in the outcome (Kinard, 1994).

Subject recruitment and retention is another difficulty encountered by researchers. There may be concerns about families involved with caseworkers and the legal system "volunteering" to participate. With treatment studies, there certainly is a selection bias in who chooses, or is chosen, to participate. Maltreating families tend to move frequently, and often do not have a phone. It is common for these families to drop out of treatment or participation in research. In addition, studies of maltreatment often utilize intrusive questions and deal with sensitive, private family matters, and many families may not wish to participate for this reason (Ammerman, 1998). Sample sizes need to be large enough to handle attrition. Although longitudinal studies are important, the time spans between assessments should not be too far apart in order to help keep in touch with these families and decrease the numbers lost (Kinard, 1994).

Another methodological problem occurs when using parental report of child behaviors. Several investigators have observed that abusive parents have negative views of their children, and these reports did not necessarily match teacher reports and/or observational ratings of child behavior (e.g., Milner and Haskett). It is unclear from the existing literature whether 
child behavior problems are actually present, or whether the perception of these problems is a result of parental or family dysfunction. Nevertheless, biased reports create many problems for the interpretation of data and implications for treatment (Reid et al., 1987). Also, many studies examining the impact of abuse focus on adults who were abused as children, and thus, rely on retrospective accounts which are open to biases (Widom, 1989). Time can distort memories, and many facts can be forgotten. In addition, these adults have had many life experiences since the abuse that may have contributed to their symptoms, and it is difficult to determine exactly what impact their experience of abuse has on their current level of functioning.

It is important to keep limitations of the literature in mind when drawing conclusions from research findings. Many results cannot be generalized further than the particular sample used in a particular investigation, and many times similar studies examining the same content often yield contradictory results. Even with these methodological problems, however, there are certain agreements that professionals come to with respect to the etiology and consequences of abuse.

\section{The ecology of maltreatment}

Child maltreatment has many proposed correlates and etiological factors. This causes difficulties in defining and conceptualizing the issues involved, yet these factors are crucial to understanding maltreated children and their families. Because it is a real possibility that some of the pre-existing conditions in high-risk families may have an impact on children above and beyond the impact of the abuse, these etiological issues deserve attention.

\subsection{Etiological models of maltreatment}

Most models of the etiology of maltreatment focus on physical abuse, although some of the concepts may generalize to sexual abuse and neglect. One of the simplest and earliest models of explaining maltreatment is the psychopathology model. This conceptualization proposed by Steele \& Pollock (1968) suggests that abuse and neglect occur because of severe psychiatric disorders, usually suggesting psychosis, or personality disturbances in the perpetrator, which in most of these cases was the parent (Ammerman, 1990). This model is not supported empirically, as estimates of psychopathology in maltreating parents is around 20\% (Ammerman, 1990). Perhaps, the interpretation of psychiatric disorder needs to be broadened. One study examined the records of a court sample of maltreating families, and found DSM-III diagnoses from licensed professionals in $84 \%$ of the parents (Taylor et al., 1991). Mental retardation/low IQ accounted for $29.8 \%$ of the diagnoses in the population, and an additional $25.7 \%$ of the diagnoses being drug and/or alcohol abuse or dependence. Approximately $28 \%$ of the parents had an affective disorder diagnosed, and 26\% were classified as a "psychosis risk". As this is a court sample, it may represent an extreme end of the population of parents who have maltreated their children.

Gelles proposed a social-cultural model that explains how the stress from societal variables like poverty and unemployment may socialize otherwise normal parents into inappro- 
priate practices (Ammerman, 1990). Parke and Collmer (1975) have tried to explain maltreatment through the social-situational model, which takes Gelles' idea a step further. Their social-situational model allows for the interaction of parent, child, and situational factors to contribute to the vulnerability of maltreatment. It examines the cognitive and affective processes, as well as observable behaviors.

Several other theories focused on multiple components and the interaction of various inter- and intra-personal factors. Belsky (1980) followed Bronfrenbrenner's model of the environment and proposed that there are four distinct levels that combine and interact to lead to maltreatment: the ontogenetic level, or the contribution of the individual parents, the microsystem or family setting, the exosystem or neighborhood and social network, and the macrosystem or greater cultural norms. The model makes a distinction between risk factors, or predispositions to abuse, and compensatory factors, which are seen as protection against maltreatment. More specific theories of the impact of variables on different levels have been described. Within the family, a parental history of abuse may, through learning theory and modeling, lead to the adoption of aggressive strategies (Belsky, 1980). The exosystem includes factors such as unemployment which can induce a sense of powerlessness, and isolation from sources of social support (Belsky, 1980). Additionally, the macrosystem, or larger social environment, has been said to hold the "cultural code" which contains the beliefs that comprise the society's childrearing system (Sameroff, 1989).

Cicchetti and Rizley (1981) expanded on Belsky's ecological model. Their transactional model includes the biological, psychological, and social elements that can either be risk or compensatory factors in maltreatment. In addition, Cicchetti and Rizley propose that the risk and compensatory factors can either be transient or enduring in nature. Wolfe (1987) also devised a model of maltreatment incorporating the multiple causes and combinations of risk and compensatory factors suggested earlier. This transitional model views abuse as the extreme end of a continuum of adequate to deviant parenting. One important aspect of these theories is that they broadened the theoretical scope to include the interaction of the family and various aspects of the home environment and individual factors, rather than just focusing on the characteristics of the parent.

Cognitive models, such as those proposed by Azar (1986) and Milner (1993), have also been introduced to explain physically abusive behavior. Milner's social information processing model is based on the assumption that parents have pre-existing cognitive schemas which include beliefs that impact the way they perceive, evaluate, integrate, and act upon child-specific information. Briefly, parents may only attend to negative cues, based on their existing schemas, even in a neutral or fairly positive situation. Their perception of these negative cues and their predisposition to make hostile attributions may lead to the interpretation that the child acted in a hostile manner, leading the parent to choose an aggressive response.

Azar's 1986 model and Azar et al., 1998, on the other hand, emphasize the importance of parental expectations of child behavior in determining responses to child-related stressful situations. Often, young children's actions do not have clear, observable motives, and assumptions and interpretations must be made by parents. However, in drawing conclusions, parents must have realistic information and expectations about what developmental skills are appropriate at certain ages, otherwise false expectations and increased frustration can result. 
Maltreating parents tend to have less information about age-appropriate behaviors (e.g., Milner \& Chilamkurti, 1991), and thus, are more prone to making faulty attributions, which may lead to increased frustration and an increased likelihood of an abusive response.

Sexual abuse usually involves dynamics in addition to these described above. A considerable portion of the child sex abuse literature has been devoted to describing characteristics of incestuous families. Typically, incest (i.e., between a father-figure and daughter) is seen to be associated with very traditional family values within an authoritarian family in which the children are subservient to the adults, and there is a patriarchal husband and a passive wife (Pelletier; Alexander and Hoagwood). Often, there is role-reversal between the mother and the daughter (Furniss and Ray). A lack of intimacy between the parents, a cold or distant relationship between the parent and child, and inconsistent parental control are typically present (Hubbard, 1989).

Very little has been written about the characteristics of families in which extrafamilial abuse has occurred. There appears to be high levels of marital conflict and family dysfunction present (Pelletier \& Handy, 1986). These families also report less cohesion and adaptability than non-abused families (Alexander \& Lupfer, 1987). Perhaps, having an authoritarian parent has taught these children to respond to the requests of adults without protest, or they give in to sex in order to get some of the affection and closeness that their family lacks (Ray et al., 1991).

\subsection{Contextual factors and child maltreatment}

Thus, many of these models focus on the parents and factors within the family environment while addressing the etiology of maltreatment. As mentioned above, there has been little empirical support for the commonly held belief that parental psychopathology (e.g., psychosis or severe mental illness) or personality factors contribute to maltreatment, but this may be due to the research methods. Studies have failed to directly address the link between parental diagnoses and the parent child relationship (Wolfe \& St. Pierre, 1989) and levels of social support.

Maltreating parents tend to be socially isolated from important sources of support (Wolfe $\&$ St. Pierre, 1989). This can be seen more globally as connected to general interpersonal skills and competence. Their isolation may be due to their poor social skills (Azar et al., 1998). Consequently, these deficits lead to poor assessments of stressful situations and an inability to generate alternative solutions, therefore increasing the likelihood that these parents will turn to violence (Wolfe \& St. Pierre, 1989). Some variables related to social support include economic hardship, marital relationships, parental psychopathology, the parent-child relationship, parenting styles, parental attributions, and discipline techniques.

Perhaps, the strongest correlate to child maltreatment is poverty or low income. In 1993, children from families with incomes under $\$ 15,000$ were 22 times more likely to experience some type of abuse than children from families with incomes above $\$ 30,000$ (NCCAN, 1996). In general, it has been thought that an association between poverty and child abuse was due to a reporting bias, in that lower income families were more likely to come to the attention of the authorities. Many replications of this finding with carefully controlled studies 
has suggested that poverty is, in its own right, a strong correlate of child abuse (Pelton and Wolfe). Specifically, the perpetration and consequences of an abusive act may be mediated by the material hardships and stresses that are inherent in an impoverished community (Pelton, 1994). Stress has been found to be a critical predictive factor of abuse, and is related to social support and family resources (e.g., Burrell et al., 1994). Thus, poverty may have a direct and indirect effect on the occurrence and consequences of an abusive act. Some evidence has also shown that the severest cases of maltreatment tend to be reported by the poorest families, suggesting that poverty may also be related to the severity of maltreatment (Pelton, 1994).

Income and social class are related to psychological distress. Unemployment, which is linked to income, has been found to be related to anxiety, depression, and hostility (Liem $\&$ Liem, 1988). Single parent homes usually tend to be experiencing economic hardship (Gelles, 1989). Single parent homes have the additional stress of increased child-rearing responsibilities and a lack or significant decrease in social support for the custodial parent. In fact, children of single parents had a 77\% greater risk of experiencing physical abuse and an $87 \%$ greater chance of experiencing sexual abuse than children in two-parent families (NCCAN, 1996). Child abuse and parental stress have been found to be linked, with the specific components of stress including low socioeconomic status, maternal depression, negative life experiences, and low marital support (Whipple and Kurtz).

One recent study by Burrell et al. (1994) found that abuse potential, stress, and social support are interrelated, with stress being the strongest correlate to abuse potential, as well as being a strong correlate to family resources and social support. The type of stress that might be the most influential is stress related to the parenting role (e.g., having a difficult child or perceiving that the child is difficult). In fact, maltreating parents report more anger, unhappiness, and rigidity with respect to their parenting role than non-maltreating parents (Wolfe, 1985). Furthermore, caregiving style and maternal sensitivity, two critical components to the parent-child relationship, are thought to be influenced by parental psychopathology, stress, and level of social support (Cicchetti \& Howes, 1991). Parents who report dissatisfaction with their support networks also report that they are dissatisfied with their roles as caregivers and tend to provide poor quality home environments for their children (Cicchetti \& Howes, 1991).

Dissatisfaction with the parenting role may be related to parental perceptions of their children. Maltreating parents tend to perceive hostile intent in their children's behaviors, and view them more negatively than non-maltreating parents (Milner \& Chilamkurti, 1991). In addition, maltreating mothers tended to make stable, internal attributions about child transgressions, and external attributions about child successes (Larrance \& Twentyman, 1983). Parental perceptions of child-rearing practices also show differences between maltreating and non-maltreating parents; abusive parents have a tendency to perceive child-rearing as more difficult and less enjoyable, and reported higher levels of anger and conflict in the family (Trickett \& Susman, 1988).

With respect to sexual abuse, interpersonal dynamics within the family, and the incest triad in particular, reflect role and boundary confusion, affective enmeshment, and poor adaptation and problem-solving abilities (Hoagwood \& Stewart, 1989). The daughter might actually feel betrayed by her father and her mother, and this perceived lack of support may lead her to feel 
isolated and report lower levels of cohesion, contrary to what would be predicted from the experience of affective enmeshment (Finkelhor \& Baron, 1986). In fact, incestuous families have been found to show lower reported levels of adaptability and cohesion (Alexander \& Lupfer, 1987). It also is possible that even before the onset of abuse, the presence of a father with an authoritarian style might be responsible for the lower levels of adaptability and cohesion (Finkelhor \& Baron, 1986). Thus, environmental variables may have an integral role in the functioning of these families without the additional factor of abuse being present.

\section{Child adjustment in response to environmental factors}

With respect to children, the main source of social support and care is from the family, thus, the quality and type of family relationships play an important role in child adjustment (Quamma \& Greenberg, 1994) and therefore will be examined here. Specifically, it is hypothesized that stress affects parents in a variety of ways, and it is the impact on parental responsiveness and sensitivity that presumably plays a role in child adjustment (Abidin et al., 1992). Two major contributors to parental responsiveness are marital satisfaction and psychopathology, and an issue related to both of these factors is the parent-child relationship. In addition, following the logic behind the etiological models of maltreatment, the greater environment also has an impact on the development of the child, such as living in impoverished conditions. As discussed earlier, poverty is also a strong correlate of child maltreatment. The research briefly reviewed in this section, concerns non-maltreating samples in order to highlight the consequences of these factors on children in general so that their adjustment can later be compared to samples of maltreated children.

\subsection{Poverty}

Poverty has long been associated with a risk of poor development, but the mechanisms connecting this variable to child outcome appear to be different from the other variables discussed. Poverty is a chronic environmental condition that in addition to exerting a direct effect on the children's lives (e.g., housing, medical care, schools, etc.), also accounts for the longevity of many stressors, and often contributes to the intergenerational transmission of adverse effects (Garmezy, 1993). Many investigators have attempted to address this issue (e.g., Attar; Halpern and Liaw), and a summary of some of the major findings is presented below. Poverty creates obstacles to sensitive nurturing. Children born into poverty are more likely to have low-birthweight (Halpern, 1990). Their parents are more likely to be single or having marital problems, and tend to be younger and less likely to have and/or utilize supportive networks (Halpern, 1990). Parents from low-income families have been seen to demonstrate more authoritarian styles of parenting and use physical punishment more often than other parents (Peterson et al., 1994). Care should be taken in making generalizations about the types of skills shown by these parents, however, as families living in poverty face different 
challenges and dangers, and more "mainstream" definitions of positive parenting may not be appropriate (Halpern, 1990).

Overall, it can be agreed that living in impoverished conditions leave children at risk to develop physical and mental health problems, as well as showing some cognitive deficits (e.g., Attar and Liaw). One explanation has been that these families are exposed to multiple risk factors, which are commonly linked to poverty (Halpern and Liaw). In fact, Garmezy \& Masten (1994) found that the presence of a single stressor led to a $1 \%$ increase in disorder, two stressors was linked to a $5 \%$ increase, and four or more stressors led to a $21 \%$ increase in subsequent pathology, highlighting the seriousness of exposure to multiple risk factors.

Perhaps, one of the most striking features of poverty is that stressors encountered in this environment are ongoing and persistent. There are many hassles and discrete events, such as witnessing violence that occur on a daily level. A recent study found that stress in urban youth did not correlate with depression and anxiety, a finding contrary to previous research (Attar et al., 1994). The researchers offered an alternative hypothesis: perhaps, when resources are scarce and the environment is dangerous, children are discouraged from depressive responses, which might label them as weak and make them easy targets (Attar et al., 1994). Perhaps, the expression of symptoms in this group of children is different.

\subsection{Marital relationships}

Given that the family is the primary source of social support for children, effects of the marital relationship on child functioning have received considerable attention. A connection between marital satisfaction and negative child outcomes has been established. People who are experiencing stress in other areas of their lives (e.g., quality of life, employment problems, depression), however, often report unhappy marriages, thus, clouding the distinction since these other stressors might also play a role in child outcome (Katz \& Gottman, 1993). Single parents who become single as a result of a divorce usually face other stressors, such as financial hardship, a decrease and shift in their social network, and more responsibility for childrearing activities. Single mothers who felt that they were not meeting their "role obligations" tended to have negative perceptions of their children (Jackson, 1994).

Also, marital discord can be seen to have a negative impact on parenting skills and the availability of parents, which in turn could account for child outcome above and beyond the witnessing of hostile and maladaptive interactions between parents (Kerig, 1995). One study showed that children who observed hostile interactions later were more likely to develop externalizing problems, and children whose fathers were emotionally distant during marital interactions were more likely to become anxious and socially withdrawn (Katz \& Gottman, 1993).

Marital relationship quality seems to have particular impact on the children's conduct problems and antisocial behavior (McMahon and Lytton). This link appears to be stronger for boys than girls, perhaps, because sons seem to be more exposed to marital conflict (Baum, 
1989). There may be a tendency for parents to shield girls from conflict, or to provide them with more support. Marital conflict has been found to be a better predictor of later adjustment problems in children than global marital distress (Cummings; Davies and Lorenz). Other researchers have hypothesized that perhaps boys intervene more in cases of frequent or severe aggression, thus, resulting in more adjustment problems (Jouriles \& LeCompte, 1991). In fact, O'Brien et al. (1995) investigated potential mediators of marital discord and its effect on children, and found that the extent to which children involve themselves or distance themselves from the conflict is a key factor. Social learning theory has commonly been employed to explain how children learn to deal with conflict through the interactions they have witnessed between their parents (e.g., O'Brien et al., 1995). Thus, children who become more engaged in the parental conflict will become exposed to more coercive and aggressive strategies which they may then employ in other situations, especially with peers. Children who tend to respond to parental conflict by seeking support elsewhere may actually be buffered from the negative impact of the parental conflict, in that they do not feel isolated or responsible for what is going on between their parents. Results of this study suggested that children who became involved in the conflict reported higher levels of anxiety and hostility and lower self-esteem than peers not using this strategy. Children seeking support from others reported less anxiety and less internalizing symptoms (O'Brien et al., 1995). Perhaps, those children who try to intervene do so because they feel responsible for the conflict, and thus, try to help. When their efforts are unsuccessful, they may be left feeling helpless and ineffectual (O'Brien et al., 1995). Children utilizing social support may have found a good buffering agent which helps them calm down and remove them from the situation, as well as reinforcing that they are not to blame (O’Brien et al., 1995).

\subsection{Parental psychopathology}

Parental psychopathology has also been examined as a precursor to child psychopathology and later functioning. Initially, a genetic component was hypothesized (Baum, 1989). Researchers have recently broadened their search and are examining some of the more indirect relationships between parental and child psychopathology (Abidin and Quamma). Although genetic links have been seen (e.g., McMahon and Frick), the effect that an individual's pathology has on the immediate social environment cannot be overlooked. In a similar fashion to marital relationships, it has been thought that parental mental illness may interfere with their ability to parent and provide a consistent, responsive, and supportive environment for children (Quamma \& Greenberg, 1994).

One study showed that children of depressed parents were exposed to more family disruption, such as more divorce and poor marital adjustment (Fendrich et al., 1990), thus, increasing the number of stressors the children experienced. These families also reported lower rates of cohesion. Another study examined children exhibiting conduct disorder and found that their parents have higher rates of reported psychopathology, marital problems, and extrafamilial interpersonal distress (McMahon \& Forehand, 1988). This suggests that parents of conduct disordered children tend to be more isolated and have less of a social network available to support them. This lack of external support, as well as their own personal difficulties 
and psychopathology might make them become easily overwhelmed with the task of parenting, thus, making them unavailable and unresponsive to their children, which, in turn, may contribute to later difficulties for these children.

Another study examined the family members of youth exhibiting drug abuse and found that disorders in these children and their siblings increased with the presence of parental depression (Luthar et al., 1993). The strongest relationships were found between maternal depression and paternal alcoholism. Maternal depression was the only disorder in parents that was consistently found to be associated with psychiatric disorders in the children, suggesting that the impact of the depression on parental responses and interactions with their children affects child outcome (Luthar et al., 1993).

Prior research has found that the parents of children or adolescents presented with a depressive disorder tend to have a higher prevalence of affective disorders than parents of children with no disorder or with a non-depressed disorder, such as anxiety (e.g., Puig-Antich et al., 1989). Most studies examining the link between parental and child psychopathology utilize samples from help-seeking populations. It is possible that children in these families may be more likely to be brought to treatment if the parents have experienced similar difficulties, thus, creating a selection bias. At least one study attempted to overcome this bias by obtaining a non-help-seeking sample of depressed children (Goodyer et al., 1993). Although this study contained only female children, the results confirmed a greater prevalence of pathology in the mothers of the non-referred depressed youth than the controls. Although major depression was the most common diagnosis, other diagnoses, such as anxiety, were present. The level of psychopathology in fathers was too low to be statistically significant in this sample, but there was a trend suggesting that fathers of depressed adolescents did have more pathology than the fathers of the controls. Interestingly, this study also linked maternal diagnosis and the number of stressful or unpleasant events experienced by the family, and found that there were significantly more stressful life events experienced in families with a maternal diagnosis (Goodyer et al., 1993). No causality was established.

\subsection{The parent-child relationship and parenting beliefs}

In researching parent-child relationships, the area of attachment has received great attention. Attachment refers to the affective tie that develops between an infant/child and the caregiver, and the behavioral system that evolves as a result. This system can be categorized as secure, suggesting that the caregiver is responsive and supportive of the child, or insecure when the caregiver does not adequately meet the child's needs or rejects the child. Prior research on the longitudinal effects of attachment show that secure attachment promotes flexibility in later problem-solving approaches, while insecure attachment in childhood may lead to aggressive and hostile behavior (Radke-Yarrow et al., 1995).

Researchers have not conclusively illustrated the mechanisms involved, but they have speculated that the patterns of maternal behavior associated with the attachment classifications might be important to later child adjustment. Mothers of securely attached children have been shown to be warmer and to display greater affection towards their children as well as more age-appropriate child rearing practices than mothers of insecurely attached chil- 
dren (Radke-Yarrow et al., 1995). As illustrated earlier, parents who are experiencing marital problems and/or psychopathology tend to have less available resources, which can lead them to be relatively unresponsive and unavailable for their children. Low self-esteem seems to be present in children who also experience psychological and/or behavioral problems (e.g., depression, aggression), and it has been demonstrated that self-concept varies with the degree of parental warmth shown (Parish \& McCluskey, 1994).

Research in family functioning has shown that the three factors of cohesion, expressiveness, and conflict appear to be related to overall family functioning and later child outcome in abusive families (Friedrich et al., 1987). Cohesion refers to the extent to which family members are connected and involved with each other (Olson, 1986). Caseworker ratings of these variables in samples of abused and non-abused children showed that greater family conflict and lower cohesion, as well as less time since the onset of abuse were related to internalizing behavior problems in the children (Friedrich et al., 1987). In general, low levels of parental support and family cohesiveness were associated with later child adjustment problems (Gold et al., 1994). Similar findings occur in non-abusive samples. An investigation of adolescents and their parents showed that low cohesion scores were associated with conduct-disordered behaviors, depression, and substance abuse (Prange et al., 1992). Family adaptability scores were correlated with conduct-disordered behaviors and anxiety (Prange et al., 1992).

A strong finding in the delinquency and conduct disorder literature is that poor parental supervision is related to acting out behaviors (Lytton; Frick and Frick). In a meta-analysis conducted by Loeber \& Stouthamer-Loeber (1986), 22 out of 29 studies reviewed found a significant correlation between parental involvement (e.g., time spent together, interest in school and friends) and externalizing behaviors. Poor parental supervision was found to be a significant correlate in 10 out of 11 studies (Loeber \& Stouthamer-Loeber, 1986).

A related issue concerns the type of parenting and discipline employed within a family. Parenting behaviors can range from an absence of concern or care for a child to severe and intrusive discipline and control over the child that results in serious physical injury. Even when severe discipline and control practices do not technically meet the criteria for abuse, it still impacts the parent-child relationship (Peterson et al., 1994). An important factor may be the presence of anger and the decision to use physical punishment rather than another discipline strategy (Peterson et al., 1994). Angry parents may be at risk for cognitive biases that lead them to perceive more negative behaviors and intentions in their children. However, one study showed that anger did not seem to be related to the choice of physical discipline, but maternal anger did correlate with a higher proportion of maternally perceived behavior problems (Peterson et al., 1994). Thus, perhaps the perception of negative behaviors and intent on the child is the critical factor in discipline.

Parental expectations of child behavior may also contribute (Azar and Azar). An examination of unrealistic parental expectations and parental interpretations was conducted to look at the impact of stress on attributions of child behavior (Azar, 1988). Mothers who had unrealistic expectations of what a child's ability level at a certain age was tended to attribute failures as intentional, hostile acts, thereby increasing their negative perceptions and emo- 
tions. Mothers with realistic knowledge of developmental expectations, however, tended to attribute failures to the task being too hard, and thus, avoided the negative schemas. When under stress, these biases were more pronounced (Azar, 1988).

\section{Child adjustment subsequent to maltreatment}

There are many research articles and reviews which delineate the consequences of maltreatment for children (cf. Ammerman; Browne; Conaway; Finkelhor and Malinosky). Overall, there seem to be deleterious effects in terms of social competence, self-esteem, autonomy, emotional adjustment, school performance, and IQ (e.g., Greenberg, in press; Kolko and Finkelhor). The effects of an abusive and/or neglectful act do not tend to develop in a predictable fashion, but rather vary as a result of the frequency, duration, and intensity of the act combined with the child's innate resources and environment (Wolfe \& McEachran, 1997). Models have been proposed to look at why these consequences develop after an abusive event occurs, and some of these will be described here. In addition, the issue of resiliency addressing children who do not appear to show serious adjustment problems will be explored. Again, due to the many methodological limitations of the research in this area, caution is needed in interpreting these findings.

\subsection{Psychopathology and development}

Child abuse, or the "battered child syndrome", was first identified publicly by the medical profession, and as such, was originally couched within the medical model (Kempe et al., 1962). Within the framework of the medical model, a disorder is considered biomedical, not bio-psycho-social, and therefore follows certain constraints: (a) the same "entity" will cause the same disorder or symptoms in all affected individuals; (b) the same symptoms at different ages should have the same cause; and (c) specific childhood disorders should lead to the same condition in adulthood (Sameroff, 1989). This definition does not fit the parameters of maltreatment. The expressions of the consequences of abuse are heterogeneous, which does not fit condition "a". In addition, the actual abusive acts often differ in description and context, and possibly cannot be defined as one "entity". Many risk factors in abuse are not disorder-specific, and may actually be related to a variety of maladaptive outcomes (Greenberg, in press). Developmental changes in psychological symptom expression are common in childhood, and certain risk factors may have differential influence at different developmental periods (Finkelhor and Greenberg, in press), thus, invalidating condition "b". Lastly, condition "c" does not allow for the presence of resilient children or developmental changes in symptom expression, and therefore does not always explain the results of maltreatment (Masten, 1989).

One of the problems with the medical model is its simplicity. Child maltreatment is typically accompanied by so many negative situations (e.g., poverty, family dysfunction) that clear developmental predictions are difficult to assume (Wolfe \& McEachran, 1997). Many 
of the etiological theories of maltreatment and developmental psychopathology also apply to the occurrence of symptoms after abuse, specifically those following an ecological approach. One basic assumption, which makes research and analysis in this field complex, is that it is unlikely that there is a single cause or correlate to a disorder; there appear to be multiple pathways to and from psychopathology, and the risk factors exist at all levels of the ecology, not just at the individual or family level (Greenberg, in press). To further complicate matters, the presence of a protective factor, or buffer, may interact with and overcome the negative effects of a risk factor, or actually may act as a preventive force against the occurrence of the risk factor (Greenberg, in press). Newberger \& DeVos (1988) discuss the importance of social cognition, environmental sensitivity, and emotional-behavioral functioning to adjustment after abuse. Specifically, the child's perceptions of the event (i.e., self-blame) may contribute to subsequent mood and behavioral changes in the child. The environmental context, or the quantity and quality of interactions with other important people in the child's life may also impact adjustment.

There are many areas of growth that occur in a child's development, and any one of them is vulnerable to disruption when a child is abused. However, these processes can and are disturbed by phenomena other than child maltreatment, and these disruptions must be separated out from trauma-specific problems (i.e., a specific fear related to an abusive event). Often, the trauma-specific disruption is localized, and although they may be persistent, they do not really impact the child's subsequent development (Finkelhor, 1995). Developmental disruptions are more likely to occur if the abuse is repetitive and ongoing, if the abuse radically changes the relationship between the child and the caregiver (such as in cases of incest), if the victimization adds to previously existing stressors in the child's life, and if the timing of the abuse interrupts a stage-salient developmental task (Finkelhor, 1995).

Developmental considerations are often overlooked in the understanding of the dynamics of abuse, specifically the vulnerability or risk of being abused, as well as the impact that an occurrence of abuse will have on the individual. Throughout childhood, individuals gain and lose characteristics that may make them more or less vulnerable for various types of victimization (Finkelhor, 1995). For example, sexual maturation tends to place children, especially girls, at an increased risk for sexual abuse. On the other hand, as children grow older, they may be more able to run away, fight back, and utilize their social networks and gain support, and therefore, are better able to protect themselves and prevent the reoccurrence of abuse. It also seems that there has been a tendency to believe that adolescents, due to their increased control over their environment, are largely responsible for their own victimization (Finkelhor, 1995). In fact, adolescents may give in to social pressures and engage in behaviors (e.g., using drugs and alcohol) that do not facilitate self-protection (Finkelhor, 1995).

The impact of abuse also appears to be closely related to developmental changes. For example, with respect to sexual abuse, hormonal secretions in preadolescent sexually abused children have been seen at abnormal levels and are associated with a variety of cognitive and behavioral effects (Finkelhor, 1995). Cognitively, an important dimension appears to be how children understand the concept of victimization and the perception of responsibility for the event (Finkelhor, 1995). Older children may be more at risk in this respect, as they are 
more able to understand the stigma associated with victimization. Also, the victim's sense of morality may be impacted, which would affect the way they view their own abuse, as well as having possible consequences on their future behaviors. Their perception of power, right and wrong, and fairness may be shaped by isolated abusive incidents, and thus, limiting the children's moral development.

Additional issues are involved in cases of sexual abuse. Specific theories about the impact of sexual abuse have been developed (e.g., Conte and Finkelhor), however, the impact of the abuse on the whole family unit seems particularly important to this discussion. Disclosure of sexual abuse differs from other family crises in that the mother is asked to believe something that she may not want to accept. She also may have to face the conflict between her roles as the primary support figure for both her partner and her child, which often are core parts of her identity (Everson and Hooper). The role of "mother" carries with it the expectation that one will protect her children, and disclosure often leads to maternal feelings of guilt and inadequacy (Hooper, 1989).

Maternal support in cases of incest have been found to be related to the intensity of the mother's relationship with the offender; specifically, mothers were the most supportive when they were no longer involved with the perpetrator (Everson et al., 1989). If the woman is still involved in the relationship, there is the potential for her to lose financial and emotional support and she appears to be more likely to deny that the abuse occurred (Orten \& Rich, 1988). Thus, disclosure of sexual abuse can lead to environmental changes, such as family members moving out of the home and changes in economic conditions which may further impact child adjustment.

Parents of children who were victims of extrafamilial abuse are also impacted by disclosure. In most of these cases, the offender is known by the family. One investigation looked at the impact on parents and found that all of the couples in the sample experienced marital problems at least in the initial period following disclosure, and many of them continued to have problems for an extended period of time (Davies, 1995). Although some of these families reported that the marital problems existed before disclosure, the stress from the abuse seemed to exacerbate them. These parents generally knew the perpetrator, and they reported that the loss of that relationship was difficult, and they had a hard time trusting adults as a result (Davies, 1995).

Obviously, the effect that disclosure has on the parent influences the support that the child will receive. As mentioned earlier, social support has been shown to contribute to psychological well being in times of stress. The literature shows that support by the parent after disclosure is clearly an important predictor of child outcome (Everson and Hazzard). The basic findings are consistent with theories of social support, and show that greater psychopathology was observed in children receiving less support (Everson et al., 1989).

\subsection{Child psychopathology associated with maltreatment}

As these models suggest, many children who experience abuse develop social, behavioral, and emotional problems. Given the potential variety of combinations of environmental risk factors and resources, personal development and characteristics, and abuse-specific variables 
(e.g., severity, duration, and frequency of the abuse), specific predictions of symptoms are difficult. Yet, there are some strong, consistent findings within the literature that suggest both short- and long-term effects (see Ammerman; Browne; Conaway; Finkelhor; Kendall; Malinosky and Neumann, for reviews). Most of these studies compare abuse victims to a non-abused cohort matched on a variety of variables (e.g., age, SES, etc.). A brief summary follows.

Children who have been physically abused have been the subjects of many empirical studies across many domains of functioning. Overall, it appears that maltreated children do show deficits and difficulties in many areas. Maltreated children tend to develop insecure attachments with their caregivers, mainly as a result of the poor, inconsistent care, rejection, and harshness of the interactions (e.g., Crittenden \& Ainsworth, 1989). Insecure attachment relationships in early childhood have been linked to later problems, such as poor peer relations, low self-esteem, aggressive behavior, and depression (e.g., Greenberg, in press). Young children who have been abused tend to respond with more aggression (Kolko, 1992). These children also tend to use less internal state language, suggesting that their knowledge of emotions and emotional regulation is compromised (Cicchetti \& Beeghly, 1987). Their social awareness may also be delayed, which potentially can lead to increased peer difficulties and interpersonal problems (e.g., Dodge and Dodge). Older children also tend to exhibit more aggressive behavior (e.g., Downey and Prino), as well as depression (Toth et al., 1992).

Physical problems can also be a result of abuse. In infants and young children, low caloric intake can result to failure to thrive and growth delays. Broken bones, severe burns, and other injuries can be a direct result of physical abuse. In many cases, adequate medical care will not be provided, as the family may try to conceal the abuse. Sexual abuse might also have some physical consequences. Aside from the risk for sexually transmitted diseases and pregnancy, there is some evidence suggesting that early abuse affects endocrine secretions, possibly resulting in the early onset of puberty (Finkelhor and Gil).

Research has found sexual abuse to be associated with a number of internalizing behaviors, including anxiety (e.g., McClellan et al., 1995), depression (e.g., Livingston and Wozencraft), suicidal ideation (e.g., Wozencraft and McClellan), and somatic complaints (e.g., Livingston, 1987). Externalizing problems have also been noted, such as self-abusive behaviors (e.g., McClellan et al., 1995), delinquency (Einbender \& Friedrich, 1989), and school problems (Einbender \& Friedrich, 1989).

Adolescent victims of sexual abuse tend to show more self-destructive behaviors, such as substance abuse, suicidal and homicidal ideation, and legal problems (Cavaiola \& Schiff, 1988). It has been suggested that antecedents of alcoholism are similar to the consequences of sexual abuse, especially the factors of social isolation and emotional disturbances (Miller et al., 1987). There have been fewer studies that have directly examined the connection between adolescent substance abuse and prior victimization, but those using in-patient samples also support the connection between sexual abuse and drug and alcohol problems (e.g., Harrison and Singer).

Victims of sexual abuse also engage in other self-destructive and risk-taking behavior significantly more than their non-abused counterparts. For example, adolescents who have been abused either physically or sexually made more suicidal ideations and attempts than those 
who were not abused (Bayatpour et al., 1992). Reviews of teen pregnancies show that 50$66 \%$ of adolescents who become mothers have a history of sexual abuse (Lanz and Rainey). These rates exceed the incidence of reported rape (15-28\%) and child sexual abuse $(25 \%)$ found in the general population (Lanz and Rainey). Pregnant teens with a history of sexual abuse also report higher levels of depression, anxiety, family dysfunction, and lower self-esteem than those without a history of victimization (Lanz and Rainey).

In addition to the effects of physical and sexual maltreatment, the impact of the psychological abuse that is inherent in these acts cannot be overlooked. Beyond the physical discomfort and social consequences of abuse, maltreatment also impacts a child's sense of self-worth (Navarre, 1987). When the adults in a child's life are abusive, it sends a message to that child about how others value him/her and perceptions of how the environment will respond to him/her (Navarre, 1987). Thus, the sense of self, individuation, and emotional regulation are potentially compromised.

\subsection{Resiliency}

Child abuse research suggests that there are a variety of outcomes after abuse, that may be short- and/or long-term, or even no-detectable harm (Kolko; Kendall and Ondersma). For example, there are estimates that as many as $50 \%$ of children who have been sexually abused may be asymptomatic (Beutler et al., 1994). Thus, it is not enough to examine how adverse reactions to abuse develop. There is much to learn from children who experience abuse but do not develop detectable adjustment problems. It is critical to note, however, that acknowledging that some children are resilient or do not experience detectable effects of abuse is not to say that abuse is ever harmless or acceptable (Ondersma et al., 1999).

Resilience has been defined as the "positive side of adaptation under adverse circumstances" (Masten, 1989). Risk research was one of the first areas to recognize the occurrence of resiliency, in great part due to the use of longitudinal designs (Masten, 1989). However, most research in the area of child adjustment does not utilize a prospective design, and thus, baseline measures of functioning are not available. The impact of stressors depends on both the current level of vulnerability and resources that the child has, as well as the intensity and duration of the stress, which is more of an interactive than a linear effect (Masten, 1989). The major difference between risk and protective factors is that risk leads directly to poorer outcomes, while protective factors act indirectly, and their effects are only detected with respect to their interaction with the risk variable (Garmezy, 1985). The timing of stress is also paramount; stressful events can have more of an impact if they occur during a critical developmental period or task (Masten, 1989).

Garmezy (1985) has described three sets of factors that appear to act as protective mechanisms: personality features (e.g., self-esteem), family cohesion and lack of discord, and the availability of external support systems. Garmezy further hypothesizes that resilience is not a trait of a person, but rather is related to the processes and current state of a person's resources and context. Women who were victimized as children and are considered resilient, or able to overcome the adversity of the abuse, reported on what helped them through the experience (Valentine \& Feinauer, 1993). They specifically mentioned that being able to find 
supportive relationships outside the family and recognizing that the abuse was not their fault were important factors. It appears, then, that both empirical observations and self-report from survivors of childhood sexual abuse show the importance of family and social support to children's outcome after a sexual trauma.

\section{Conclusion}

It appears that many of the symptoms children experience after abuse, with the exception of physical injuries and sexual behaviors, are similar to those exhibited by non-abused children exposed to many of the same environmental risk factors. Interpretations must be made cautiously, however, given the limitations of the existing research. Child maltreatment is a multidimensional construct, and is difficult to study. Some of the many limitations of the research include, but are not limited to, definitional problems and the identification of adequate control populations, sampling biases for both the maltreating and control groups, subject recruitment and retention, and biases in parental report of child behavior. Many studies employ small samples, and there is usually some concern about controlling for confounding variables.

Nevertheless, the research suggests that environmental characteristics, such as poverty, the quality of marital relationships, parental psychopathology, the quality of the parent child relationship, and parenting beliefs all are correlated with the risk of maltreatment. Each risk factor has been investigated in its own right, with non-maltreated populations, and carries potential consequences for child adjustment. Specifically, poverty is a condition that co-exists with many other stressors, and children raised in impoverished conditions are at risk to develop physical and mental health problems, as well as some cognitive deficits (e.g., Attar and Liaw). Marital and relationship difficulties appear to have an impact on the development

of conduct problems and antisocial behavior in children (McMahon and Lytton). Children of parents suffering from a form of psychopathology, such as depression or substance abuse, are more likely to have an affective disorder (e.g., Puig-Antich et al., 1989), or to abuse drugs themselves (e.g., Luthar et al., 1993). Insecure attachments between a child and his or her parents has been linked to later psychological and/or behavior difficulties, such as depression and aggression (e.g., Radke-Yarrow et al., 1995). Poor parental supervision, which may be present in families where there is also marital discord, parental psychopathology, and/or poverty, has been linked with delinquency and conduct disorder (e.g., Lytton and Frick). Children who have experienced maltreatment similarly have been characterized as having emotional difficulties (i.e., depression and anxiety), school difficulties and lower IQs, as well as problems with aggression and acting out behaviors (Ammerman; Conaway; Kolko; Kendall; Finkelhor and Greenberg, in press).

It seems clear that the increased number and interaction of environmental risk factors, including the abuse, that many maltreated children experience may lead, in some cases, to an increased severity of their symptoms and problems. It is also likely that in some cases, the impact of maltreatment is not discernable from or an addition to the impact from other environ- 
mental risk factors which can lead to similar consequences. Given the many methodological challenges in the field, including the number and complexity of the relevant variables (e.g., environmental risk factors, maltreatment characteristics, and possible outcomes), it is also apparent that we have much to learn and may never answer all of our questions.

Even if the children are not presently showing adverse consequences of the abuse, or if the current adjustment problems of the children are attributed to other causes, the act is still wrong, and protective and preventive action should be taken. Research and statistical methodology do not allow for the determination of causality or a definitive breakdown of variance, therefore, it is difficult to determine exactly how these factors, the abusive act and the environmental context, may interact and contribute to the development of adjustment problems. Perhaps more importantly, abusive acts violate the ethical and moral standards of the treatment of people in our society, and therefore merit attention, regardless of what the impact on the child may be. The actions of the adult perpetrator certainly suggest that they are in need of services.

Once a family has entered the system, an interesting dichotomy typically emerges between the parents and the children. In cases of physical abuse, the parents are referred for treatment, and unless the child is acting in a harmful way, the child is not required to receive therapy. Most programs for perpetrators of physical abuse and neglect focus on parenting strategies, anger control, and problem solving (e.g., Wolfe; Barth; Azar and Azar). Many physically abused children do eventually present for treatment, usually as a result of their disruptive behaviors or severe emotional problems, and not directly because they have been identified as physically abused. When a child is sexually abused, however, families are encouraged to get the child therapy, and the non-offending parent often does not get any help. Programs for sexual offenders focus on the sexual offense and assault cycle, yet also include anger management and problem solving (e.g., Marshall et al., 1991). If the variables involved in maltreatment encompass the family and the parent-child relationship, it seems important that both the children and adults receive treatment. Individual pathology issues should be addressed, but family therapy to repair relationships and address environmental issues is also warranted.

Every year, more and more American families live in conditions which have been identified as being risk factors for child psychopathology: poverty, marital discord, parental psychopathology, etc. Yet there is not a widespread public or professional outcry to help these children. Families are given the right to privacy, and the freedom to raise their children the way they see fit. Once that arbitrary line is crossed, however, and an abusive act has been identified, the law has the right to step in on behalf of the children.

Maltreating families tend to have a combination of risk factors and stressors that many other families also face. These risk factors, such as poverty, marital discord, parental psychopathology, and problematic parenting strategies, not only put families at risk for abuse but also put children at risk for adjustment problems, whether or not abuse is present. While addressing these risk factors in our society is an obviously needed strategy, we can also look to the research on resilience for possible areas of intervention. As Garmezy (1985) notes, there 
are factors that tend to buffer a child from the adverse effects of his or her environment, such as personality factors (e.g., self-esteem), family cohesion and lack of discord, and external support systems. Resilient children do exist, suggesting that if these buffers are present, they can override the negative impact of problematic environmental conditions to a large degree. Thus, interventions that help prevent or reduce the occurrence of these risk factors, promote positive emotional and behavioral development of children, and provide their families with better support can help children at risk. Secondary prevention efforts, such as the current programs to treat perpetrators and victims of abuse must continue, but primary prevention efforts must be expanded.

\section{References}

Abidin, R.R., Jenkins, C.L. and McGaughey, M.C., 1992. The relationship of early family variables to children's subsequent behavioral adjustment. J Clin Child Psychol 21, pp. 60-69.

Alexander, P.C. and Lupfer, S.L., 1987. Family characteristics and long-term consequences associated with sexual abuse. Arch Sex Behav 16, pp. 235-245.

Ammerman, R.T., 1990. Etiological models of child maltreatment: a behavioral perspective. Behav Modif 14, pp. 230-254.

Ammerman, R.T., 1998. Methodological issues in child maltreatment research. In: Lutzker, J.R., Editor, , 1998. Handbook of Child Abuse Research and Treatment, Plenum, New York, pp. 117-132.

Ammerman, R.T., Cassisi, J.E., Hersen, M. and Van Hasselt, V.B., 1986. Consequences of physical abuse and neglect in children. Clin Psychol Rev 6, pp. 291-310.

Attar, B.K., Guerra, N.G. and Tolan, P.H., 1994. Neighborhood disadvantage, stressful life events, and adjustment in urban elementary-school children. J Clin Child Psychol 23, pp. 391-400.

Azar, S.T., 1986. A framework for understanding child maltreatment: an integration of cognitive behavioral and developmental perspectives. Can J Behav Sci 18, pp. 340-355.

Azar, S. T. (1988). Child-rearing stress and attributional processes: An examination of a cognitive-behavioral model of child maltreatment. Paper presented at the Association for Advancement of Behavior Therapy. November 1988. New York.

Azar, S.T., (1989). Training parents of abused children. In: Schaefer, C.E. and Briesmeister, J.M., Editors, 1989. Handbook of Parent Training: Parents as Cotherapists for Children's Behavior Problems, Wiley, New York, pp. 414-441.

Azar, S.T., Povilaitis, T.Y., Lauretti, A.F. and Pouquette, C.L., 1998. The current status of etiological theories in intrafamilial child maltreatment. In: Lutzker, J.R., Editor, , 1998. Handbook of Child Abuse Research and Treatment, Plenum, New York, pp. 3-30.

Azar, S.T. and Siegel, B.R., (1990). Behavioral treatment of child abuse: a developmental perspective. Behav Modif 14, pp. 279-300.

Azar, S.T. and Twentyman, C.T., (1986). Cognitive behavioral perspectives on the assessment and treatment of child abuse. In: Kendall, P.C., Editor, , 1986. Advances in Cognitive Bheavioral Research and Therapy vol. 5, Academic Press, New York, pp. 237-267.

Barth, R.P., Blythe, B.J., Schinke, S.P., Stevens, P. and Schilling, R.F., 1983. Self control training with maltreating parents. Child Welfare 62, pp. 313-323.

Baum, C.G., 1989. Conduct disorders. In: Ollendick, T.H. and Hersen, M., Editors, 1989. Handbook of Child Psychopathology (2nd edn. ed.), Plenum, New York, pp. 171-196.

Bayatpour, M., Wells, R.D. and Holford, S., 1992. Physical and sexual abuse as predictors of substance abuse and suicide among pregnant teenagers. $J$ Adolesc Health 13, pp. 128-132. 
Belsky, J., 1980. Child maltreatment: an ecological integration. Am Psychol 35, pp. 320-335.

Beutler, L.E., Williams, R.E. and Zetzer, H.A., 1994. Efficacy of treatment for victims of child sexual abuse. Future Child: Sex Abuse Child 4, pp. 156-175.

Browne, A. and Finkelhor, D., 1986. Impact of child sexual abuse: a review of the research. Psychol Bull 99, pp. 66-77.

Burrell, B., Thompson, B. and Sexton, D., 1994. Predicting child abuse potential across family types. Child Abuse Neglect 18, pp. 1039-1049.

Cavaiola, A.A. and Schiff, M., 1988. Behavioral sequelae of physical and/or sexual abuse in adolescents. Child Abuse Neglect 12, pp. 181-188.

Cicchetti, D. and Beeghly, M., 1987. Symbolic development in maltreated youngsters: an organizational perspective. In: Cicchetti, D. and Beeghly, M., Editors, 1987. New Directions for Child Development: No. 36. Symbolic Development in Atypical Children, Jossey-Bass, San Francisco, pp. 5-29.

Cicchetti, D. and Howes, P.W., 1991. Developmental psychopathology in the context of the family: illustrations from the study of child maltreatment. Can J Behav Sci 23, pp. 257-281.

Cicchetti, D. and Rizley, R., 1981. Developmental perspectives on the etiology, intergenerational transmission, and sequelae of child maltreatment. New Directions Child Dev 11, pp. 31-55.

Conaway, L.P. and Hansen, D.J., 1989. Social behavior of physically abused and neglected children: a critical review. Clin Psychol Rev 9, pp. 627-652.

Conte, J.R., 1985. The effects of sexual abuse on children: a critique and suggestions for future research. Victimology 10, pp. 110-130.

Crittenden, P.M. and Ainsworth, M.D.S., 1989. Child maltreatment and attachment theory. In: Cicchetti, D. and Carlson, V., Editors, 1989. Child Maltreatment: Theory and Research on the Causes and Consequences of Child Abuse and Neglect, Cambridge Univ. Press, New York, pp. 432-463.

Cummings, E.M. and Davies, P., 1994. Children and Marital Conflict: The Impact of Family Dispute and Resolution, Guilford Press, New York.

Davies, M.G., 1995. Parental distress and ability to cope following disclosure of extra-familial sexual abuse. Child Abuse Neglect 19, pp. 399-408.

Davies, P.T. and Cummings, E.M., 1994. Marital conflict and child adjustment: an emotional security hypothesis. Psychol Bull 116, pp. 387-411.

Dodge, K.A., Bates, J.E. and Pettit, G.S., 1990. Mechanisms in the cycle of violence. Science 250, pp. 16781683.

Dodge, K.A., Pettit, G.S. and Bates, J.E., 1994. Effects of physical maltreatment on the development of peer relations. Dev Psychopathol 6, pp. 43-55.

Downey, G. and Walker, E., 1992. Distinguishing family-level and child-level influences on the development of depression and aggression in children at risk. Dev Psychopathol 4, pp. 81-95.

Einbender, A.J. and Friedrich, W.N., 1989. Psychological functioning and behavior of sexually abused girls. J Consulting Clin Psychol 57, pp. 155-157.

Everson, M.D., Hunter, W.M., Runyon, D.K., Edelsohn, G.A. and Coulter, M.L., 1989. Maternal support following disclosure of incest. Am J Orthopsychiatry 59, pp. 197-207.

Fendrich, M., Warner, V. and Weissman, M.M., 1990. Family risk factors, parental depression, and psychopathology in offspring. Dev Psychol 26, pp. 40-50.

Finkelhor, D., 1990. Earl and long term effects of child sexual abuse: an update. Prof Psychol: Res Practice 21, pp. 325-330.

Finkelhor, D., 1995. The victimization of children: a developmental perspective. Am J Orthopsychiatry 65, pp. 177-193.

Finkelhor, D. and Baron, L., 1986. High-risk children. In: Finkelhor, D., Editor, , 1986. A Sourcebook on Child Sexual Abuse, Sage Publications, Newbury Park, CA, pp. 60-88. 
Finkelhor, D. and Browne, A., 1985. The traumatic impact of sexual abuse: a conceptualization. Am J Orthopsychiatry 55, pp. 530-541.

Frick, P.J. and Jackson, Y.K., 1993. Family functioning and childhood antisocial behavior: yet another reinterpretation. J Clin Child Psychol 22, pp. 410-419.

Frick, P.J., Lahey, B.B., Loeber, R., Stouthamer-Loeber, M., Christ, M.A.G. and Hanson, K., 1992. Familial risk factors to oppositional defiant disorder and conduct disorder: parental psychopathology and maternal parenting. J Consulting Clin Psychol 60, pp. 49-55.

Friedrich, W.N., Beilke, R.L. and Urquiza, A.J., 1987. Children from sexually abusive families: a behavioral comparison. J Interpers Violence 2, pp. 391-402.

Furniss, T., 1984. Conflict-avoiding and conflict-regulating patterns in incest and child sexual abuse. Acta Paedopsychiatria 50, pp. 299-313.

Garmezy, N., 1985. Stress resistant children: the search for protective factors. In: Stevenson, J.E., Editor, , 1985. Recent Research in Developmental Psychopathology, Pergamon, New York, pp. 213-233.

Garmezy, N., 1993. Children in poverty: resilience despite risk. Psychiatry 56, pp. 127-136.

Garmezy, N. and Masten, A.M., 1994. Chronic adversities. In: Rutter, M., Taylor, E. and Hersov, L., Editors, 1994. Child and Adolescent Psychiatry: Modern Approaches (3rd edn. ed.),, Blackwell, Cambridge, MA, pp. 191-208.

Gelles, R.J., 1989. Child abuse and violence in single parent families. Am J Orthopsychiatry 59, pp. 492-500.

Gil, E., 1996. Treating Abused Adolescents, Cambridge Univ. Press, New York.

Gold, S.R., Milan, L.D., Mayall, A. and Johnson, A.E., 1994. A cross-validation study of the trauma symptom checklist. J Interpers Violence 9, pp. 12-26.

Goodyer, I.M., Cooper, P.J., Vize, C.M. and Ashby, L., 1993. Depression in 11-16-year-old girls: the role of past parental psychopathology and exposure to recent life events. J Child Psychol Psychiatry Allied Discip 34, pp. 1103-1115.

Greenberg, M.T., in press. Attachment and psychopathology in childhood. In J. Cassidy \& P.R. Shaver (Eds.), Handbook of Attachment Theory and Research. New York: Guilford Press.

Halpern, R., 1990. Poverty and early childhood parenting: toward a framework for intervention. Am J Orthopsychiatry 60, pp. 6-18.

Hansen, D.J., Warner-Rogers, J.E. and Hecht, D.B., 1998. Implementing and evaluating an individualized behavioral intervention program for maltreating families: clinical and research issues. In: Lutzker, J.R., Editor, , 1998. Handbook of Child Abuse Research and Treatment, Plenum, New York.

Harrison, P.A., Hoffman, N.G. and Edwall, G.E., 1989. Sexual abuse correlates: similarities between male and female adolescents in chemical dependency treatment. J Adolesc Res 4, pp. 382-399.

Haskett, M.E., Scott, S.S. and Fann, K.D., 1995. Child abuse potential inventory and parenting behavior: relationships with high-risk correlates. Child Abuse Neglect 19, pp. 1483-1495.

Hazzard, A., Celano, M., Gould, J., Lawry, S. and Webb, C., 1995. Predicting symptomatology and self-blame among child sex abuse victims. Child Abuse Neglect 19, pp. 707-714.

Hoagwood, K. and Stewart, J.M., 1989. Sexually abused children's perceptions of family functioning. Child Adolesc Soc Work 6, pp. 139-149.

Hooper, C., 1989. Alternatives to collusion: the response of mothers to child sexual abuse in the family. Educ Child Psychol 6, pp. 22-30.

Houck, G.M. and King, M.C., 1989. Child maltreatment: family characteristics and developmental consequences. Issues Mental Health Nurs 10, pp. 193-208.

Hubbard, G.B., 1989. Mothers' perceptions of incest: sustained disruption and turmoil. Arch Psychiatr Nurs 3, pp. 34-40.

Jackson, A.P., 1994. The effects of role strain on single, working, black mothers' perceptions of their young children. Soc Work Res 18, pp. 36-40. 
Jouriles, E.N. and LeCompte, S.H., 1991. Husbands' aggression toward wives and mothers' and fathers' aggression toward children: moderating effects of child gender. J Consulting Clin Psychol 59, pp. 190-192.

Katz, L.F. and Gottman, J.M., 1993. Patterns of marital conflict predict children's internalizing and externalizing behaviors. Dev Psychol 29, pp. 940-950.

Kempe, C.H., Silverman, F.N., Steele, B.F., Droegemuller, W. and Silver, H.K., 1962. The battered child syndrome. J Am Med Assoc 191, pp. 17-24.

Kendall-Tackett, K.A., Williams, L.M. and Finkelhor, D., 1993. Impact of sexual abuse on children: a review and synthesis of recent empirical studies. Psychol Bull 113, pp. 164-180.

Kerig, P.K., 1995. Triangles in the family circle: effects of family structure on marriage, parenting, and child adjustment. J Fam Psychol 9, pp. 28-43.

Kinard, E.M., 1994. Methodological issues and practical problems in conducting research on maltreated children. Child Abuse Neglect 18, pp. 645-656.

Kolko, D.J., 1992. Characteristics of child victims of physical violence: research findings and clinical implications. J Interpers Violence 7, pp. 244-276.

Kurtz, P.D., Gaudin, J.M., Howling, P.T. and Wodarski, J.S., 1993. The consequences of physical abuse and neglect on the school age child: mediating factors. Child Youth Serv Rev 15, pp. 85-104.

Lanz, J.B., 1995. Psychological, behavioral, and social characteristics associated with early forced sexual intercourse among pregnant adolescents. J Interpers Violence 10, pp. 188-200.

Larrance, D.T. and Twentyman, C.T., 1983. Maternal attributions and child abuse. J Abnorm Psychol 92, pp. 449-457.

Liaw, F. and Brooks-Gunn, J., 1994. Cumulative familial risks and low-birthweight children's cognitive and behavioral development. J Clin Child Psychol 23, pp. 360-372.

Liem, R. and Liem, J.H., 1988. Psychological effects of unemployment on workers and their families. J Soc Issues 44 , pp. 87-105.

Livingston, R., 1987. Sexually and physically abused children. J Am Acad Child Adolesc Psychiatry 26, pp. 413415.

Loeber, R. and Stouthamer-Loeber, M., 1986. Family factors as correlates and predictors of juvenile conduct problems and delinquency. In: Tonry, M. and Morris, N., Editors, 1986. Crime and Justice 17, Univ. Chicago Press, Chicago, pp. 29-149.

Lorenz, G., Hoven, C., rews, H.F. and Bird, H., 1995. Marital discord and psychiatric disorder in children and adolescents. J Child Fam Stud 4, pp. 341-358.

Luthar, S.S., Merikangas, K.R. and Rounsaville, B.J., 1993. Parental psychopathology and disorders in offspring: a study of relatives of drug abusers. J Nerv Ment Dis 181, pp. 351-357.

Lytton, H., 1990. Child and parent effects in boys' conduct disorder: a reinterpretation. Dev Psychol 26, pp. 683697.

Malinosky-Rummell, R. and Hansen, D.J., 1993. Long-term consequences of childhood physical abuse. Psychol Bull 114, pp. 68-79.

Marshall, W.L., Jones, R., Ward, T., Johnston, P. and Barbaree, H.E., 1991. Treatment outcome with sex offenders. Clin Psychol Rev 11, pp. 465-485.

Masten, A.S., 1989. Resilience in development: implications of the study of successful adaptation for developmental psychopathology. In: Cicchetti, D., Editor, 1989. The Emergence of a Discipline: Rochester Symposium on Developmental Psychopathology vol. 1, Lawrence Erlbaum Associates, Publishers, Hillsdale, NJ, pp. 261-294.

McClellan, J., Adams, J., Douglas, D., McCurry, C. and Storck, M., 1995. Clinical characteristics related to severity of sexual abuse: a study of seriously mentally ill youth. Child Abuse Neglect 19, pp. 1245-1254.

McMahon, R.J. and Forehand, R., 1988. Conduct disorders. In: Mash, E.J. and Terdal, L.G., Editors, 1988. Behavioral Assessment of Childhood Disorders (2nd edn. ed.),, Guilford Press, New York, pp. 105-156. 
Miller, B.A., Downs, W.R., Gondoli, D.M. and Keil, A., 1987. The role of childhood sexual abuse in the development of alcoholism in women. Violence Victims 2 (3), pp. 157-172.

Milner, J.S., 1993. Social information processing and physical child abuse. Clin Psychol Rev 13, pp. 275-294.

Milner, J.S. and Chilamkurti, C., 1991. Physical child abuse perpetrator characteristics: a review of the literature. J Interpers Violence 6, pp. 345-366.

Milner, J.S. and Robertson, K.R., 1990. Comparison of physical child abusers, intrafamilial sexual child abusers, and child neglecters. $J$ Interpers Violence 5, pp. 37-48.

National Center on Child Abuse and Neglect (NCCAN), 1996. Third National Incidence Study of Child Abuse and Neglect, US Department of Health and Human Services, Washington, DC.

Navarre, E.L., 1987. Psychological maltreatment: the core component of child abuse. In: Brassard, M.R., Germain, R. and Hart, S.N., Editors, 1987. Psychological Maltreatment of Children and Youth, Pergamon, New York, pp. 45-56.

Neumann, D.A., Houskamp, B.M., Pollock, V.E. and Briere, J., 1996. The long-term sequelae of childhood sexual abuse in women: a meta-analytic review. Child Maltreat 1, pp. 6-16.

Newberger, C.M. and DeVos, E., 1988. Abuse and victimization: a life-span developmental perspective. Am J Orthopsychiatry 58, pp. 505-511.

O’Brien, M., Margolin, G. and John, R.S., 1995. Relation among marital conflict, child coping, and child adjustment. J Clin Child Psychol 24, pp. 346-361.

Olson, D.H., 1986. Circumplex model VII: validation studies and FACES III. Fam Process 25, pp. 337-351.

Ondersma, S.J., Chafin, M. and Berliner, L., 1999. Comments on the Rind et al. meta-analysis controversy. APSAC Advisor 12 (3), pp. 2-5.

Orten, J.D. and Rich, L.L., 1988. A model for assessment of incestuous families. Soc Casework: J Contemp Soc Work 69, pp. 611-619.

Parish, T.S. and McCluskey, J.J., 1994. The relationship between parenting styles and young adults' self-concepts and evaluations of parents. Fam Ther 21, pp. 223-226.

Parke, R.D. and Collmer, C.W., 1975. Child abuse: an interdisciplinary analysis. In: Hetherington, E.M., Editor, , 1975. Review of Child Development Research vol. 5, Univ. Chicago Press, Chicago, pp. 509-590.

Pelletier, G. and Handy, L.C., 1986. Family dysfunction and the psychological impact of child sexual abuse. Can J Psychiatry 31, pp. 407-412.

Pelton, L.H., 1994. The role of material factors in child abuse and neglect. In: Melton, G.B. and Barry, F.D., Editors, 1994. Protecting Children from Abuse and Neglect: Foundations for a New National Strategy, Guilford Press, New York, pp. 131-181.

Peterson, L., Ewigman, B. and Vandiver, T., 1994. Role of parental anger in low-income women: discipline strategy, perceptions of behavior problems, and the need for control. J Clin Child Psychol 23, pp. 435-443.

Prange, M.E., Greenbaum, P.E., Silver, S.E., Friedman, R.M., Kutash, K. and Duchnowski, A.J., 1992. Family functioning and psychopathology among adolescents with severe emotional disturbances. $J$ Abnorm Child Psychol 20, pp. 83-102.

Prino, C.T. and Peyrot, M., 1994. The effect of child physical abuse and neglect on aggressive, withdrawn, and prosocial behavior. Child Abuse Neglect 18, pp. 871-884.

Puig-Antich, J., Goetz, D., Davies, M., Kaplan, T., Davies, S., Ostrow, L., Asnis, L., Twomey, J., Iyengar, S. and Ryan, N., 1989. A controlled family history study of prepubertal major depressive disorder. Arch Gen Psychiatry 46, pp. 406-418.

Quamma, J.P. and Greenberg, M.T., 1994. Children's experience of life stress: the role of family social support and social problem-solving skills as protective factors. J Clin Child Psychol 23, pp. 295-305.

Radke-Yarrow, M., McCann, K., DeMulder, E., Belmont, B., Martinez, P. and Richardson, D.T., 1995. Attachment in the context of high-risk conditions. Dev Psychopathol 7, pp. 247-265.

Rainey, D.Y., Stevens-Simon, C. and Kaplan, D.W., 1995. Are adolescents who report prior sexual abuse at higher risk for pregnancy?. Child Abuse Neglect 10, pp. 1283-1288. 
Ray, K.C., Jackson, J.L. and Townsley, R.M., 1991. Family environments of victims of intrafamilial and extrafamilial child sexual abuse. J Fam Violence 6, pp. 365-374.

Reid, J.B., Baldwin, D.V., Patterson, G.R. and Dishion, T., 1987. Some problems relating to the assessment of childhood disorders: a role for observational data. In: Rutter, M., Tuma, H. and Lann, I., Editors, 1987. Assessment and Diagnosis in Child and Adolescent Psychopathology, Guilford Press, New York, pp. 156-195.

Sameroff, A.J., 1989. Models of developmental regulation: the environtype. In: Cicchetti, D., Editor, , 1989. The Emergence of a Discipline: Rochester Symposium on Developmental Psychopathology vol. 1, Lawrence Erlbaum Associates, Publishers, Hillsdale, NJ, pp. 261-294.

Singer, M.I., Song, L. and Ochberg, B., 1994. Sexual victimization and substance abuse in psychiatrically hospitalized adolescents. Soc Work Res 18, pp. 97-103.

Steele, B. J., \& Pollock, C. (1968). A psychiatric study of parents who abuse infants and small children. In R.R. Hefler \& C. H. Kempe (Eds.), The Battered Child ( pp. 89-133). Chicago: University Chicago Press.

Taylor, C. G., Norman, D. K., Murphy, J. M., Jellenik, M., Quinn, D., Poitrast, F. G., \& Goshko, M. (1991). Diagnosed intellectual and emotional impairment among parents who seriously mistreat their children: prevalence, type, and outcome in a court sample. Child Abuse Neglect 15, 389-401.

Toth, S. L., Manly, J. T., \& Cicchetti, D. (1992). Child maltreatment and vulnerability to depression. Dev Psychopathol 14, 97-112.

Trickett, P. K., \& Susman, E. J. (1988). Parental perceptions of child-rearing practices in physically abusive and non-abusive families. Dev Psychol 24, 270-276.

Valentine, L., \& Feinauer, L. L. (1993). Resilience factors associated with female survivors of child sexual abuse. Am J Fam Ther 21, 216-224.

Whipple, E. E., \& Webster-Stratton, C. (1991). The role of parental stress in physically abusive families. Child Abuse Neglect 15, 279-291.

Widom, C.S., 1989. Does violence beget violence? A critical examination of the literature. Psychol Bull 106, pp. $3-28$.

Wolfe, D.A., 1985. Child-abusive parents: an empirical review and analysis. Psychol Bull 97 3, pp. $462-482$.

Wolfe, D.A., 1987. Child Abuse: Implications for Child Development and Psychopathology, Sage Publications, Newbury Park, CA.

Wolfe, D.A. and McEachran, A., 1997. Child physical abuse and neglect. In: Mash, E.J. and Terdal, L.G., Editors, 1997. Assessment of Childhood Disorders (3rd edn. ed.),, Guilford Press, New York, pp. 523-568.

Wolfe, D.A., Sandler, J. and Kaufman, K., 1981. A competency based parent training program for abusive parents. J Consulting Clin Psychol 49, pp. 633-640.

Wolfe, D.A. and St. Pierre, J., 1989. Child abuse and neglect. In: Ollendick, T.H. and Hersen, M., Editors, 1989. Handbook of Child Psychopathology (2nd edn. ed.),, Plenum, New York, pp. 377-398.

Wozencraft, T., Wagner, W. and Pelligrin, A., 1991. Depression and suicidal ideation in sexually abused children. Child Abuse Neglect 15, pp. 505-511. 